\title{
Evaluation of the wound healing activity of formulated ointments and water preparation from Sida rhombifolia leaf extract
}

PATRICK FRANCIS ${ }^{*}$, PAX MASIMBA ${ }^{1}$ and AMOS R. MWAKIGONJA2

${ }^{1}$ Department of Biological and Preclinical Studies, Institute of Traditional Medicine, Muhimbili University of Health and Allied Sciences, Box 65001, Dar es Salaam, Tanzania

${ }^{2}$ Department of Pathology, Muhimbili University of Health and Allied Sciences, Box 65001, Dar es Salaam, Tanzania

\begin{abstract}
Background: Several plants including Sida rhombifolia Linn. (Malvaceae) which are said to be used by traditional health practitioners in Tanzania for wound treatment have not yet been evaluated. The objective of this study was to investigate the ointment formulation of S. rhombifolia leaves for its potential wound healing activities.

Methods: Wound healing activity of S. rhombifolia leaves was investigated in mice using 50\%, 33\% and $25 \%$ formulated $80 \%$ ethanolic leaves extract ointment and water preparations. Excisional and incisional wound-induction models were used with 6 albino mice in each group. The wound diameter (for contraction assessment), duration of re-epithelisation in days, percentage tensile strength as well as the degree of collagenisation and fibrosis were investigated.

Results: S. rhombifolia leaves extract had significant mean percentage wound closure for all ointment formulations used and for the water preparation from day 7. A significant percentage tensile strength on day 10 for all formulations used was observed. The $50 \%$ ointment had a mean of $64.1 \pm 1.7\left(p=1.2^{-09}\right), 33 \%$ ointment had a mean of $64.0 \pm 3.2\left(p=2.4^{-08}\right)$ and the $25 \%$ ointment had a mean of 53.1 $\pm 4.0\left(p=1.3^{-06}\right) . A$ remarkable fibrosis and collagenisation for the $50 \%$ ointment and the water preparation was observed. Conclusion: The formulated ointments and the water preparations of S. rhombifolia leaves have a potential benefit in enhancing wound healing. A bioassay guided fractionation is recommended to allow identification of its active compound(s) with wound healing activity for drug development.
\end{abstract}

Keywords: wound, healing, activity, ointment, Sida rhombifolia, leaves, Tanzania

\section{Introduction}

Wounds represent a major health burden and a drain on healthcare resources globally. The majority of Africans still utilize traditional medicine for their health-care needs including the treatment of various forms of wounds (Agyare et al., 2009). It has been documented that both traditional and modern medicine are being used together in wound treatment mostly for minor injuries as well as for male circumcision in Tanzania (Mboera et al., 2009; Maregesi et al., 2016a). In this regard, the use of traditional and alternative medicine for wound management has been made possible through people's improved perception towards the same as well as the incorporation of new concepts to expedite the wound healing process in traditional medicine. Furthermore, the documentation of several studies in wound care management using herbal and traditional medicine from different continents is increasing (Molan, 2006). These wound healing herbal extracts are said to fight infection, promote blood clotting and accelerate the healing process of wounds (Kumarasamyraja et al., 2012).

Some of the plants that have been documented to be used by traditional health practitioners in Tanzania for management of wounds include Azadirachta indica, Sida rhombifolia, Balanites aegyptiaca, Trichodesma zeylanicum, Melanthera scandens, Rytigynia celastroides and Hugonia castaneifolia (Muanza et al., 1994; Mgole et al., 2007; Moshi et al., 2010; Yadav \& Panghal, 2010; Lupala et al., 2014; Baylor, 2015). S. rhombifolia has many characteristics which suggest it to have wound healing activity which led to the choice of the plant for in vivo wound healing testing. First, the aqueous and methanolic root extracts of this plant showed effective free radical

\footnotetext{
*Correspondence E-mail: pafki2008@gmail.com
} 
scavenging activity, reducing power, superoxide scavenging activity and moderate antibacterial activity in some bacterial species (Dhalwal et al., 2007; Assam et al., 2010; Narendhirakannan \& Limmy, 2012; Woldeyes et al., 2012). Secondly, hydro-alcoholic extract of S. rhombifolia leaves exhibits a significant anti-inflammatory activity which is a good indication of wound healing property (Logeswari et al., 2013). Thus, our current study aims to explore the wound health activity of S. rhombifolia leaves.

\section{Materials and methods}

\section{Study design}

This was an experimental pre-clinical in-vivo study conducted at the Institute of Traditional Medicine (ITM), Muhimbili University of Health and Allied Sciences (MUHAS) in Dar es Salaam, Tanzania. With the aid of a field botanist, S. rhombifolia leaves were collected from Kwasemangube village in Korogwe, Tanzania. The leaves were harvested, shade dried, sorted and grounded. Voucher specimens were prepared and kept in the herbarium of University of Dar es salaam and of ITM-MUHAS.

\section{Preparation}

About $0.8 \mathrm{~kg}$ of powdered leaves was placed in a glass percolator with 3 litres of $80 \%$ ethanol and allowed to stand at room temperature for 48 hours. The percolate was collected two times and the combined extract was concentrated by using a rotary evaporator at the temperature of $60^{\circ} \mathrm{C}$. Approximately, $200 \mathrm{ml}$ of the concentrated extract was evaporated to dryness using a freeze dryer to yield the dry powdered extract. Water preparations of S. rhombifolia was done by mixing $25 \mathrm{gm}$ of ground fresh leaves with $50 \mathrm{ml}$ of water to get a paste which was applied on wound topically as test substance in order to access wound healing activity in the preparation form which was assumed to be equivalent to the one used by traditional healers. Adopting the method of Zahi et al. (2015), 80\% ethanolic extract of the S. rhombifolia leaves was incorporated into simple ointment base to make $25 \%, 33 \%$ and $50 \%$ formulations by triturating in a ceramic mortar and pestle to obtain herbal ointments (Table 1).

Table 1: Ratios and composition of plant extracts and ointment in grams

\begin{tabular}{lllll}
\hline Dosage & Extract weight & Ointment weight & Total & \% Extract (W/W) \\
\hline $1000 \mathrm{mg} / \mathrm{Kg}$ & 7.5 & 7.5 & 15 & $50 \%$ \\
$500 \mathrm{mg} / \mathrm{Kg}$ & 7.5 & 15 & 22.5 & $33 \%$ \\
$250 \mathrm{mg} / \mathrm{Kg}$ & 2.5 & 10 & 12.5 & $25 \%$ \\
\hline
\end{tabular}

\section{Experimental animals}

The study used white albino mice of either sex (25-30 gm), aged 8 weeks, obtained from the animal house of ITM-MUHAS. The animals were acclimatized for 5 days and kept in separate cages in groups assigned randomly for wound healing monitoring. The animals were given access to light 12 hours a day and fed ad-libitum. Animal handling and care followed internationally accepted principles for humane laboratory animal use. Ethanol (70\%) was used as antiseptic for the shaved region before making the wound. The mice were anaesthetized with ether and hairs were removed by shaving the dorsal back of the mice using a razor blade.

An excision wound of $8 \mathrm{~mm}$ diameter was made by removing a full thickness piece of the skin from a predetermined shaved area using a biopsy punch which caused two circular wounds of equal size on both sides. The wounds were left undressed to the open environment and no local or systemic anti-microbial agents was used ( Subhashini \& Arunachalam, 2011; Rashed et al., 2003). In the second post-wounding day, six groups of mice were created by randomization of animals. The three formulated herbal ointment (50\%, 33\% and $25 \%$ ), positive (Povidone lodine), the water 
preparation and negative (simple ointment) control were topically applied on the excised wounds at two days intervals to the four treatment groups.

From the $3^{\text {rd }}$ post-wounding day, wounds were traced using a divider at four days interval. The animals were restrained in proper position during tracing and the tracings were then transferred to $1 \mathrm{~mm}^{2}$ graph paper and the size of the wound diameter scored. Wound diameters were read and the percentages of wound contraction were calculated taking the initial size as $100 \%$. Wound closure $(\%)=\left(A_{0}-A_{n}\right) \times 100 \% / A_{0}$ where $A_{0}$ is the initial wound diameter, and $A_{n}$ is the wound diameter at the time interval of 4 days. Where $n=$ number of days $3^{\text {rd }}, 7^{\text {th }}, 11^{\text {th }}$ and $15^{\text {th }}$.

\section{Re-epithelisation and histopathological assessment}

The healing duration was considered as the number of days the wound disappeared macroscopically without any residue from each animal (Kommu, 2013). The number of days reepithelisation occurred from each group were recorded in a separate sheet and their averages were determined. After wounds had healed, animals in each group were sacrificed and the wound parts were excised together with the surrounding skin. They were then fixed in $10 \%$ neutral wellbuffered formalin. Microscopic examination of the wound bed material was performed on haematoxylin and eosin stained $5 \mu \mathrm{m}$ thick paraffin sections as previously described (Geethalakshmi et al., 2013; Maregesi et al., 2016b). The sections were assessed under the light microscope and graded semi-quantitatively in respect of the proliferation of fibroblast cells and collagenisation (Shukla et al., 1999; Bhat et al., 2016). The semi-quantitative grading was done using a scale up: - (equivocal/minimal/mild), + (weak), ++ (moderate) and +++ (remarkable) as previously described (Pes et al., 2010).

A one $\mathrm{cm}$ longitudinal incision was made on the midline of the vertebral column of each mouse after shaving. A surgical thread (No. 2/0) and a curved needle ( $1 / 2$ circle $50 \mathrm{~mm}$ ) were used for the stitching $0.5 \mathrm{~mm}$ from the edge of the wound. The wounds were then left undressed to the open environment and no local or systemic anti-microbial agents was used as previously described (Rashed et al., 2003; Subhashini \& Arunachalam, 2011). On the second day post-wounding, five groups of mice were formed by randomization process. Each group received one of the following; $50 \%$ formulated herbal ointment, 33\% formulated herbal ointment, $25 \%$ formulated herbal ointment, Povidone lodine (positive control) and simple ointment base (negative control) which were topically applied on the incised wound on daily basis. One group was left untreated identified as untreated group. The sutures were then removed on the $7^{\text {th }}$ day and skin breaking strength was measured by continuous water flow method on day 10 (Shukla et al., 1999).

\section{Tensile strength determination}

Skin breaking strength was measured by a designed tensiometer which consisted of a $3 \times 6 \times 12$ inch wooden board platform with two posts fixed on a retort stand on each side of the wooden platform. A pulley was mounted on the clamp on another retort stand. An alligator clamp was tied on another post in such a way that the clamp could reach the middle of the board. Another alligator clamp was tied on a longer fishing line and a 0.5 litres polyethylene bottle was tied on the other end passing through the pulley to make the polyethylene bottle suspended free in air at $90^{\circ}$ as previously described (Mukherjee et al., 2000).

Before testing, the mice were euthanized and each mouse was placed on the wooden board. The clamps were then carefully clamped on the skin on opposite sides of the wound at a distance of $0.5 \mathrm{~cm}$ from the wound. The longer piece of fishing line was placed on the pulley and finally to the polyethylene bottle and the position of the board was adjusted so that the bottle suspended in air. Water was added slowly in the polyethylene bottle until wound was reopened. The weight of both polyethylene bottle and added water were considered as the tensile strength of the wound. The percentage tensile strength was calculated using the formula described below:

\%Tensile strength (TS) of test sample $=(\text { TS of test sample }- \text { TS s:0 })^{*} 100 / T S$ s:0

$\%$ Tensile strength $($ TS $)$ of reference $=($ TS of reference-TS s:o $) * 100 /$ TS s:0 
\%Tensile strength (TS) of s:o $=($ TS s:o-TS I:u)*100/TS I:u

Where, s.o and l.u stand for simple ointment (vehicle) treated and left untreated groups respectively (Gebrehiwot et al., 2015).

\section{Data analysis}

Microsoft Excel program was used to run data analysis using One way ANOVA followed by Tukey's method to assess the significant difference between test groups and that of controls. Differences between means were considered significant at $p \leq 0.05$.

\section{Results}

\section{Wound contraction}

The percentage of wound diameter contraction for animals treated with S. rhombifolia leaves extract was significant from day 7 to 15 in two formulations; the $50 \%$ as well as the $33 \%$ ointments when compared to the negative control. Furthermore, it was also observed that, the $50 \%$ ointment formulation showed significant mean percentage wound diameter contraction on day 7, 11, and day 15 as compared to the negative control. In addition, the $33 \%$ ointment formulation had significant mean percentage wound diameter contraction on day 7, 11, and day 15 as compared to the negative control. On the other hand, when compared to the negative control, the $25 \% \mathrm{~S}$. rhombifolia ointment formulation showed a significant mean percentage wound diameter contraction of 97.9 \pm 2.1 (Table 2) on day 15. The water preparation also, exhibited significant wound contraction on day 7, 11 and 15 when compared to the negative control. No any tested material showed significant wound diameter contraction comparable to that of standard drug (Povidone iodine) used. The mean percentage wound diameter contraction for the untreated group of mice was significantly different from the positive control group for all examined days $(p<0.05$, Table 2$)$.

Table 2: Effect of different S. rhombifolia $80 \%$ ethanolic leaves extract formulations and water preparation on wounds diameters

\begin{tabular}{lllllll}
\hline & Negative control & $25 \%$ & $33 \%$ & $50 \%$ & Water preparation & $\begin{array}{l}\text { Positive } \\
\text { control }\end{array}$ \\
\hline Day3 & $4.2 \pm 1.3$ & $6.3 \pm 1.6$ & $6.3 \pm 2.3$ & $8.3 \pm 2.1$ & $7.3 \pm 1.9$ & $17.7 \pm 1.9^{*}$ \\
Day7 & $33.3 \pm 3.1$ & $40.6 \pm 1.4$ & $44.8 \pm 2.5^{*}$ & $45.8 \pm 2.1^{*}$ & $43.8 \pm 2.3^{*}$ & $63.5 \pm 1.9^{*}$ \\
Day11 & $63.8 \pm 3.1$ & $73.6 \pm 3.0$ & $78.1 \pm 2.7^{*}$ & $79.2 \pm 2.6^{*}$ & $79.2 \pm 1.3^{*}$ & $92.7 \pm 3.4^{*}$ \\
Day15 & $81.3 \pm 2.0$ & $97.9 \pm 2.1^{*}$ & $100 \pm 0^{*}$ & $100 \pm 0^{*}$ & $97.9 \pm 2.1^{*}$ & $100 \pm 0^{*}$ \\
\hline
\end{tabular}

The values are the mean percentage contraction of wound diameters calculated using ANOVA followed by Tukey's method for comparison. *Means $\mathrm{p}<0.05$ and (Significant against negative control)

\section{Re-epithelisation}

As shown in Table 3, neither the ointment formulations nor the water preparation of Sida rhombifolia leaves extract showed significant mean re-epithelisation days over negative control.

Table 3: Effect of different formulated herbal ointments on wounds epithelisation

\begin{tabular}{llll}
\hline Formulation & Negative control & Sida rhombifolia & Positive control \\
\hline $50 \%$ & $18.8 \pm 0.3$ & $17.2 \pm 0.3$ & $16.7 \pm 0.4^{*}$ \\
$33 \%$ & $18.8 \pm 0.3$ & $17.8 \pm 0.3$ & $16.7 \pm 0.4^{*}$ \\
$25 \%$ & $18.8 \pm 0.3$ & $18.0 \pm 0.4$ & $16.7 \pm 0.4^{*}$ \\
Water preparation & $18.8 \pm 0.3$ & $17.3 \pm 0.4$ & $16.7 \pm 0.4^{*}$ \\
\hline
\end{tabular}

Values are means percentages of epithelisation days calculated using ANOVA followed by Tukey's method for comparison. * Means $\mathrm{p}<0.05$ (Significant against negative control) 


\section{Tensile strength results and histopathological results}

All formulated ointments used had significant mean percentage tensile as shown in Table 4.

Table 4: Effect of herbal formulations on tensile strength of wounds

\begin{tabular}{llll}
\hline Dose/group & Negative control & Sida rhombifolia & Positive control \\
\hline $50 \%$ & $10.7 \pm 1.2$ & $64.1 \pm 1.7^{*}$ & $98.0 \pm 3.8^{*}$ \\
$33 \%$ & $10.7 \pm 1.2$ & $64.0 \pm 3.2^{*}$ & $98.0 \pm 3.8^{*}$ \\
$25 \%$ & $10.7 \pm 1.2$ & $53.1 \pm 4.0^{*}$ & $98.0 \pm 3.8^{*}$ \\
\hline
\end{tabular}

The values are the mean percentage tensile strength calculated using ANOVA followed by Tukey's method for comparison. *Means $\mathrm{p}<0.05$ (Significant against vehicle control.)

The $50 \%$ Sida rhombifolia leaves ointment formulation as well as the water preparation were found to have remarkable fibroblast cells proliferation and collagenisation (Table 5; Figure 1). However, there was also associated moderate inflammation in all the water preparations.

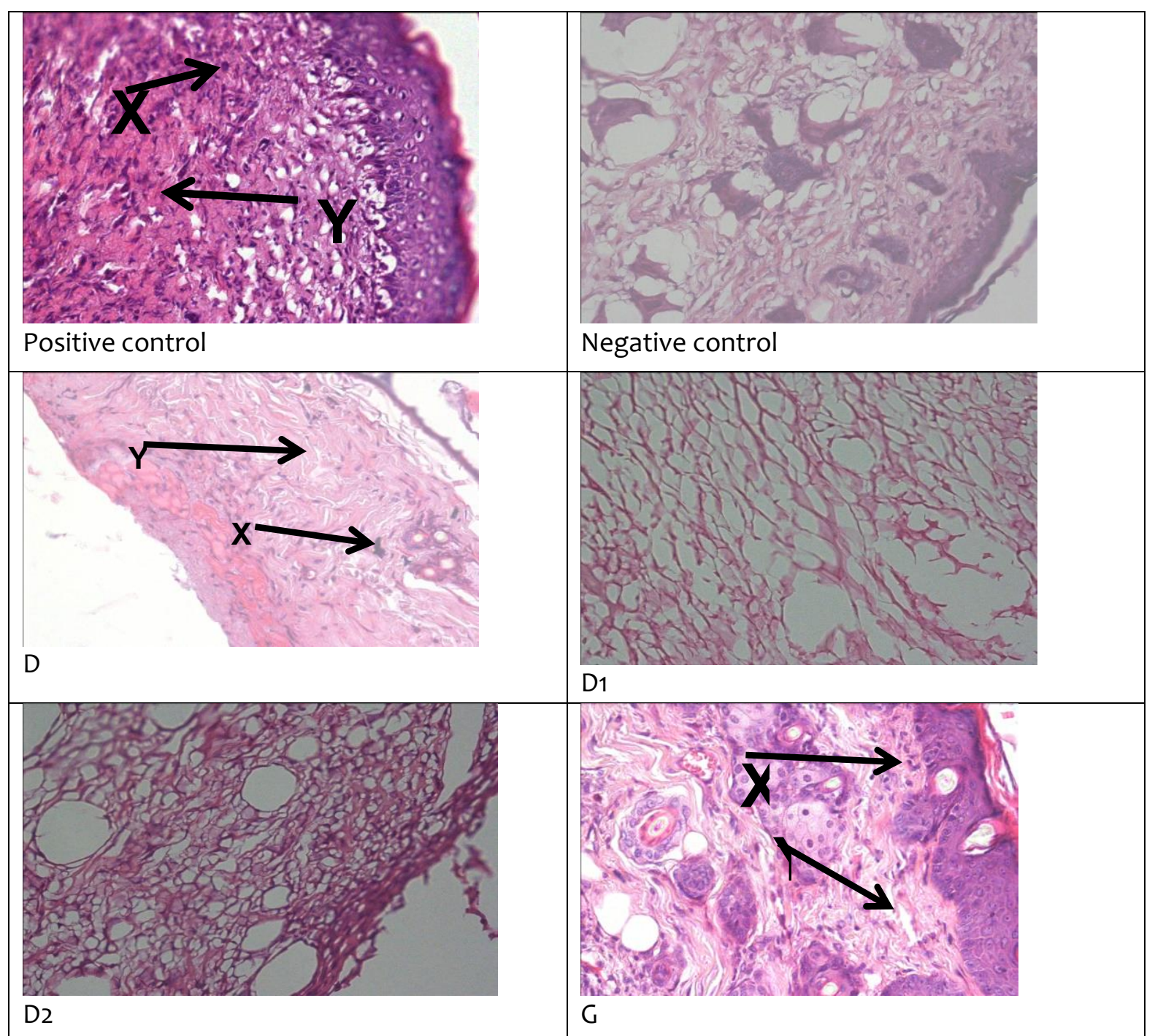

Figure 1: H\&E stained microscopic mice skin sections of tissues from the healed area of the wounds from different groups, treated with different herbal formulations at $\mathbf{x} \mathbf{4 0}$ magnification (The $X$ arrow shows fibrosis (Blue) and the $Y$ arrow shows deposited collagen (Pink). (D) Treated with 50\%, (D1) Treated with 33\%, (D2) Treated with $25 \%$ and (G) Treated with water preparation) 
Table 5: Histological assessment results

\begin{tabular}{lll}
\hline Test group & Fibroblast cells & Collagen fibre \\
\hline Positive Control & ++ & ++ \\
$50 \%$ & +++ & +++ \\
$33 \%$ & ++ & ++ \\
$25 \%$ & + & + \\
Water preparation & +++ & +++ \\
Negative control & ++ & ++ \\
\hline
\end{tabular}

Key: + =weak; ++ =moderate; +++ =remarkable

\section{Discussion}

In the present study three parameters for wound healing activity were investigated, percentage wound contraction, tensile strength of skin and the period of re-epithelisation. According to these results, S. rhombifolia leaf formulations at different percentages tested, significantly enhanced the rate of wound healing as indicated by higher mean percentage of wound diameter contraction and higher tensile strength of the wound tissues as compared to negative controls. The ointment formulation at 50\% showed significant wound contraction from day 7 post wounding which was closer to that of the standard drug (Povidone iodine). This formulation increased the collagen content of the skin which ultimately contributed to increased wound tensile as also shown in the results. The collagenisation was complimented by the remarkable fibrosis which was also associated with this formulation.

It should also be noted that previous reports have indicated that the wound healing effects of S. rhombifolia could partly be attributed to their antibacterial and antioxidant properties as evidenced in their ability to inhibit bacteria growth and protect fibroblast cells against oxidant injury (Dhalwal et al., 2007; Kiessoun et al., 2012; Logeswari et al., 2013). The wound healing properties of S. rhombifolia may also be contributed to by the phytochemical constituents present in the plant. This plant species has been reported to have tannins, polyphenols, alkaloids, glycosides, flavonoids and saponins all of which play different roles in wound healing (Sapna et al., 2016).

A numbers of compounds isolated from S. rhombifolia leaves have been demonstrated in vitro as active principles responsible for facilitating healing of wounds such as antibacterial, antifungal, ant-inflammatory and antioxidant activities (Dhalwal et al., 2007; Assam et al., 2010; Poojari, 2011; Narendhirakannan \& Limmy, 2012; Woldeyes et al., 2012). It has further been previously reported that, S. acuta and S. cordifolia which belong to the same family as S. rhombifolia showed antimicrobial activity and significant wound healing activity in incisional and excisional models (Ekpo \& Etim, 2009; Akilandeswari et al., 2010). These reports corroborate the results observed in the current study, since all the species are under the same Genus, they are likely to contain relatively similar compounds responsible for wound healing activity. The remarkable fibrosis and collagenisation for water preparation suggest that the plants may have compounds which promote healing and repair. This also suggests that probably the wound healing compounds from these plants may be more water soluble.

The findings in this study suggest that the $80 \%$ ethanolic extract and the water preparation of S. rhombifolia leaves have a potential benefit in enhancing the wound healing process. This observation corroborates its use in traditional medicine in the treatment of wounds. The observed efficacy may possibly be attributed to the presence of different compounds in the extracts which are known to contribute in the wound healing properties of this plant. It is therefore recommended that, more fractionation and isolation studies be done to identify active compound(s) in Sida rhombifolia leaves which are responsible for the wound healing activity. 


\section{References}

Agyare, C., Asase, A., Lechtenberg, M., Niehues, M., Deters, A. \& Hensel, A. (2009) An ethnopharmacological survey and in vitro confirmation of ethnopharmacological use of medicinal plants used for wound healing in Bosomtwi-Atwima-Kwanwoma area, Ghana. Journal of Ethnopharmacology 125: 393-403.

Akilandeswari, S., Senthamarai, R., Valarmathi, R. \& Prema, S. (2010)Wound healing actvity of Sida acuta in rats. International Journal of PharmTech Research 2: 585-587.

Assam J.P., Dzoyem C.A. \& Pieme, V.B. (2010) In vitro antibacterial activity and acute toxicity

studies of aqueous-methanol extract of Sida rhombifolia Linn (Malvaceae). BMC Complementary and Alternative Medicine 10:40

Baylor, J. (2015) Analysis of Traditional Medicine in Zanzibar, Tanzania. Independent Study Project (ISP) Collection.

Bhat, P.B., Hegde, S., Upadhya, V., Hegde, G.R., Habbu, P.V. \& Mulgund, G.S. (2016) Evaluation of wound healing property of Caesalpinia mimosoides Lam. Journal of Ethnopharmacology 193: 712-724.

Dhalwal, K., Deshpande, Y.S. \& Purohit, A.P. (2007) Evaluation of in vitro antioxidant activity of Sida rhombifolia (L.) Ssp . retusa (L.). Journal of Medicinal Food 10:683-688.

Ekpo, M.A. \& Etim, P.C. (2009) Antimicrobial activity of ethanolic and aqueous extracts of Sida acuta on microorganisms from skin infections. Journal of Medicinal Plants Research 3: 621624.

Gebrehiwot, M., Asres, K., Bisrat, D., Mazumder, A., Lindemann, P. \& Bucar, F. (2015) Evaluation of the wound healing property of Commiphora guidottii Chiov. ex. Guid. BMC Complementary and Alternative Medicine 15, 282.

Geethalakshmi, R., Sakravarthi, C., Kritika, T., Arul Kirubakaran, M. \& Sarada, D.V.L. (2013) Evaluation of antioxidant and wound healing potentials of Sphaeranthus amaranthoides Burm.f. BioMed Research International Article ID 607109.

Kiessoun, K., Jacques Francois, M., Maurice, O., Alexis, N.L., Alain, S., N. Nicolas, B. \& Bertrand, M. (2012) Preliminary toxicity study, anti-nociceptive and anti-inflammatory properties of extracts from Sida rhombifolia I. (malvaceae). International Journal of Pharmaceutical Sciences and Research 3: 3136-3145.

Kommu, S. (2013) Evaluation of wound healing activity of methanolic extract of Balanites aegyptiaca L. leaves. International Journal of Pharmacy and Pharmaceutical Sciences 5: 7-8.

Kumarasamyraja, D., Jeganathan, N.S. \& Manavalan, R. (2012) A review on medicinal plants with potential wound healing activity. International Journal of Dermatology $\quad$ 2:105-111.

Logeswari, P., Dineshkumar, V., Prathap. S.M. \& Usha, P.T.A. (2013) In-vivo antiinflammatory effect of aqueous and ethanolic extract of Sida rhombifolia L. root. International Journal of Pharmaceutical Sciences and Research 4: 8232.

Lupala, J.M., Mdemu, M.V. \& Butungo, S.P. (2014) Effects of peri-urban land use changes on forest ecosystem services: the case of settlements surrounding Pugu and Kazimzumbwi Forest Reserves in Tanzania. Journal of Geography and Geology 6: 231-240.

Maregesi, S.M., Kauke, B., Kagashe, G. \& Kaali, R. (2016a) Traditional Eye Medicines in Tanzania: Products, Health Risk Awareness and Safety Evaluation. Herbal Medicine 2:1.

Maregesi, S.M., Mwakigonja, A.R. \& Urio, P. (2016b) Toxicity evaluation of Abrus precatorius seeds collected from Bunda District, Tanzania. Scholars Academic Journal of Pharmacy 5: 399-405.

Maver, T., Maver, U., Stana Kleinschek, K., Smrke, D.M., Kreft, S. \& Faculty, M. (2015) A review of herbal medicines in wound healing. International Journal of Dermatology 54: 740-751.

Mboera, L.E.G., Massaga, J.J., Senkoro, KP., Kilima, S.P., Mayala, B.K., Msovela, J. \& Shayo, E.H. (2009) Challenges and opportunities for the involvement of traditional practitioners in 
scaling up of safe male circumcision in the context of HIV prevention in Tanzania. National Institute for Medical Research, Dar es Salaam, Tanzania.

Mgole, S., David, O., Pieters, L. \& Vlietinck, A.J. (2007) Ethnopharmacological survey of the Bunda district, Tanzania : Plants used to treat infectious diseases. Journal of Ethnopharmacology 113: 457-470.

Molan, PC. (2006) Using honey in wound care. International Journal of Clinical Aromatherapy France 3(2b): 21-24.

Moshi, M.J., Otieno, D.F., Mbabazi, P.K. \& Weisheit, A. (2010) Ethnomedicine of the Kagera Region, north western Tanzania. Part 2: The medicinal plants used in Katoro Ward, Bukoba District. Journal of Ethnobiology and Ethnomedicine 6: 19.

Muanza, D.N., Kim, B.W., Euler, K.L. \& Williams, L. (1994) Antibacterial and antifungal activities of nine medicinal plants from Zaire. International Journal of Pharmacognosy 32: 337-345.

Mukherjee, P.K., Verpoorte, R. \& Suresh, B. (2000) Evaluation of in-vivo wound healing activity of Hypericum patulum (Family: Hypericaceae ) leaf extract on different wound model in rats. Journal of Ethnopharmacology 70: 315-321.

Narendhirakannan, R.T. \& Limmy, T.P. (2012) Anti-inflammatory and anti-oxidant properties of Sida rhombifolia stems and roots in adjuvant induced arthritic rats. Immunopharmacology and Immunotoxicology 34: 326-336.

Pes, I., Baykal, T., Alper, M. \& Yes, E. (2010) Investigations on the in vivo wound healing potential of Hypericum perforatum L . Journal of Ethnopharmacology 127: 468-477.

Poojari, R. (2011) Phytochemical fingerprinting, cytotoxic, antimicrobial, antitubercular, antimycotic potentials of Sida rhombifolia Sub sp. Asia Pacific Journal of Life Sciences 4: 201-214.

Rashed, A.N., Afifi, F.U. \& Disi, A.M. (2003) Simple evaluation of the wound healing activity of a crude extract of Portulaca oleracea L. (growing in Jordan) in Mus musculus. Journal of Ethnopharmacology 88: 131-136.

Sapna, S., Anju, D. \& Sanju, N. (2016) Traditional Indian medicinal plants with potential wound healing activity: a review. International Journal of Pharmaceutical Sciences and Research 7: 1809-1819.

Shukla, A., Rasik, A.M., Jain, G.K., Shankar, R., Kulshrestha, D.K. \& Dhawan, B.N. (1999) In vitro and in vivo wound healing activity of asiaticoside isolated from Centella asiatica. Journal of Ethnopharmacology 65: 1-11.

Subhashini, S. \& Arunachalam, K.D. (2011) Investigations on the phytochemical activities and wound healing properties of Adhatoda vasica leave in Swiss albino mice. African Journal of Plant Science 5: 133-145.

Woldeyes, S., Adane, L., Tariku, Y., Muleta, D. \& Begashaw, T. (2012) Evaluation of antibacterial activities of compounds isolated from Sida rhombifolia Linn. (Malvaceae). Natural Product Chemical \& Research 1: 2-8.

Yadav, J. \& Panghal, M. (2010) Balanites aegyptiaca (L.) Del. (Hingot): a review of its traditional uses, phytochemistry and pharmacological properties. International Journal of Green Pharmacy 4: 140.

Zahi, A.K., Hamzah, H., Hutheyfa, S., Shaari, M.R., Sithambaram, S. \& Othman, H.H. (2015) Acute and sub-acute dermal toxicity studies of Morinda citrifolia fruit extract in sprague dawley rats. Asian Journal of Pharmerceutical and Clinical Research 8(2). 